\title{
Optimal design and energy management of a renewable energy plant with seasonal energy storage
}

\author{
Hilal Bahlawan ${ }^{1 *}$, Enzo Losi ${ }^{1}$, Lucrezia Manservigi ${ }^{1}$, Mirko Morini ${ }^{2}$, Michele Pinelli ${ }^{1}$, Pier Ruggero Spina $^{1}$, Mauro \\ Venturini ${ }^{1}$ \\ ${ }^{1}$ Dipartimento di Ingegneria, Università degli Studi di Ferrara, 44122 Ferrara, Italy \\ ${ }^{2}$ Dipartimento di Ingegneria e Architettura, Università degli Studi di Parma, 43124 Parma, Italy
}

\begin{abstract}
The exploitation of fossil fuels is undoubtedly responsible of environmental problems such as global warming and sea level rise. Unlike energy plants based on fossil fuels, energy plants based on renewable energy sources may be sustainable and reduce greenhouse gas emissions. However, they are unpredictable because of the intermittent nature of environmental conditions. For this reason, energy storage technologies are needed to meet peak energy demands thanks to the stored energy. Moreover, the renewable energy systems composing the plant must be optimally designed and operated. Therefore, this paper investigates the challenge of the optimal design and energy management of a grid connected renewable energy plant composed of a solar thermal collector, photovoltaic system, ground source heat pump, battery, one short-term thermal energy storage and one seasonal thermal energy storage. To this aim, this paper develops a methodology based on a genetic algorithm that optimally designs a $100 \%$ renewable energy plant with the aim of minimizing the electrical energy taken from the grid. The load profiles of thermal, cooling and electrical energy during a whole year are taken into account for the case study of the Campus of the University of Parma (Italy).
\end{abstract}

\section{Introduction}

In recent years, several attempts have been made to reduce greenhouse gas emissions by means of the integration of Renewable Energy Sources (RESs) within energy plants. To this aim, the European Commission has planned, for the power sector, an increase of the RES share to more than $80 \%$ by 2050 [1]. In addition, some countries have moved towards $100 \%$ renewable energy scenarios, supported by recent studies (e.g., [2, 3]) that demonstrated the technical feasibility of this ambitious goal.

In Europe, most of heating and cooling energy demand is still covered by means of fossil fuel, so that several studies (e.g., [4]) recommended the combined production of heating and power. Such a purpose can be achieved by means of combined heat and power systems, power to gas, power lo liquid, power to heat, electrical and Thermal Energy Storages (TESs).

It is worth noting that energy storage technologies promote RES integration, since the exceeding energy can be stored and subsequently exploited based on user energy demand. In such a manner, the mismatch between RES availability and actual energy demand can be overcome. In addition, energy storage also increases the flexibility of the energy plant, while energy losses during start-up and shut-down manoeuvres can be reduced [5].

In the literature, both thermal and electrical energy storage technologies are generally divided into shortterm and long-term energy storages. According to Guelpa and Verda [6], short-term TESs generally handle the daily thermal peak request, because thermal energy can be stored from some hours to one day. Instead, in long-term TESs, namely Seasonal TESs (STESs), thermal energy can be stored for a longer period, even up to several months [6]. In such a manner, thermal energy can be collected during the summer season and provided when peaks of thermal energy demand occur, i.e., in winter season.

Sørensen et al. [7] documented a district heating production plant in which one short-term TES and one seasonal STES are included for meeting the heat demand by means of only RESs. However, as highlighted in that study, thermal losses may significantly affect TES operation, so that reliable tools tuned for their evaluation are crucial. To this aim, Cadau et al. [5] developed a novel and accurate model that provided a detailed insight into heat exchange

\footnotetext{
*Corresponding author: hilal.bahlawan@unife.it
} 
phenomena and temperature variations within stratified sensible TES.

Regarding electrical energy storage technologies, Saboori et al. [8] stated that flywheels, superconducting energy storages and small-scale batteries are the most renowned short-term storage technologies, while pumped-storages, compressed air energy storages and large-scale batteries represent the available solutions for long-term storage.

Among these alternatives, Van der Kam and Van Sark [9] highlighted the leading role of batteries, demonstrating that they will provide up to $90 \%$ of the stored electricity.

In this framework, the current paper aims at investigating the optimal design and energy management of a grid connected Renewable Energy Plant (REP) considering the thermal, cooling and electrical energy demands of the Campus of University of Parma (Italy).

The novelty of the paper relies on the considered case study that, for the first time, is designed for meeting the $100 \%$ RES target. Instead, for the same case study, Bahlawan et al. [10] and Zatti et al. [11, 12] investigated a hybrid energy plant configuration.

In the current paper, the energy plant configuration comprises a Solar Thermal Collector (STC), Photovoltaic system (PV), Ground Source Heat Pump (GSHP), Battery Energy Storage (BES), short-term TES and STES. In addition, the connection to the electrical grid can be exploited only to meet the electrical energy demand, whereas the surplus of electrical energy produced from the PV cannot be delivered to the grid. This choice relies on the fact that exportation of electrical energy to the grid is not allowed in all regions worldwide [10].

It is worth noting that, among several electrical storage alternatives, a short-term BES is considered in this paper, since this technology has reached a reasonable technical maturity as well as cost competitiveness [8].

Finally, a TES and a STES are considered. In fact, sensible storage technologies represent a relatively mature technology compared to other options (i.e., latent and thermochemical storages), whose study, development and market availability, especially for seasonal purposes, should be further investigated. In addition, among several sensible storage alternatives, hot-water storages are less dependent on the hydrogeological features of the environment, thus being a feasible solution for almost any location [13].

The optimal design and the energy management of the considered REP are identified by means of a Genetic Algorithm (GA) with the aim of minimizing the electrical energy taken from the grid. This optimization tool has been selected thanks to its ability to handle discrete space and nonlinear problems [14].

\section{Materials and methods}

In this paper, the sizes of the REP components are optimized by implementing a model in Matlab ${ }^{\circledR}$. The analysis is carried out by considering one year of operation and a time step of one hour.

The sizing optimization problem is solved by using a GA. More details about the GA used in this paper can be found in Bahlawan et al. [14]. As shown from Fig. 1, the REP is composed of a STC, PV, GSHP, TES, STES and BES.

The GSHP is considered reversible, i.e., it is used to fulfil the thermal energy demand during winter and midseason, while it is used to meet the cooling energy demand during summer. Moreover, the STES is charged during summer and discharged during winter and midseason.

Equations (1), (2) and (3) represent the thermal, cooling and electrical energy balances, respectively, written for each time step $\mathrm{k}$ :

$$
\begin{aligned}
& E_{\mathrm{u}, \mathrm{th}, \mathrm{k}}=E_{\mathrm{STC}, \mathrm{th} \rightarrow \mathrm{u}, \mathrm{k}}+E_{\mathrm{GSHP}, \mathrm{th}, \mathrm{k}}+E_{\mathrm{STES}, \mathrm{th}, \mathrm{out}, \mathrm{k}}+E_{\mathrm{TES}, \mathrm{th}, \mathrm{out}, \mathrm{k}} \\
& E_{\mathrm{u}, \mathrm{cool}, \mathrm{k}}=E_{\mathrm{GSHP}, \mathrm{cool}, \mathrm{k}} \\
& E_{\mathrm{u}, \mathrm{el}, \mathrm{k}}+E_{\mathrm{GSHP}, \mathrm{el}, \mathrm{k}}=E_{\mathrm{PV}, \mathrm{el} \rightarrow \mathrm{u}, \mathrm{k}}+E_{\mathrm{BES}, \mathrm{el}, \mathrm{out}, \mathrm{k}}+E_{\text {grid,el,k }}
\end{aligned}
$$

As can be seen from Eq. (1), the thermal energy demand of the user $\left(E_{\mathrm{u}, \mathrm{th}, \mathrm{k}}\right)$, can be met by the STC, GSHP, STES and TES systems. In Eq. (2), the cooling energy demand of the user $\left(E_{\mathrm{u}, \mathrm{cool}, \mathrm{k}}\right)$ can only be met by the GSHP. Finally, as reported in Eq. (3), the electrical energy demand of the user $\left(E_{\mathrm{u}, \mathrm{el}, \mathrm{k}}\right)$ and the electrical energy required to run the GSHP is met by the PV and the BES systems, while, in case of shortage, electricity is taken from the grid.

Equation (4) states that the thermal energy produced from the STC is used to meet the thermal energy demand and to fill up the TES and STES. The TES can be charged and discharged throughout the year, while the STES is supposed to be charged during summer and used to meet the thermal energy demand during winter.

From Eq. (5), the electrical energy produced from the PV is used to meet the electrical energy demand of the user, the GSHP and to charge the batteries. Moreover, the option of selling electricity to the grid is not allowed.

$E_{\mathrm{STC}, \mathrm{th}, \mathrm{k}}=E_{\mathrm{STC}, \mathrm{th} \rightarrow \mathrm{u}, \mathrm{k}}+E_{\mathrm{STC}, \mathrm{th} \rightarrow \mathrm{TES}, \mathrm{k}}+E_{\mathrm{STC}, \mathrm{th} \rightarrow \mathrm{STES}, \mathrm{k}}$

$E_{\mathrm{PV}, \mathrm{el}, \mathrm{k}}=E_{\mathrm{PV}, \mathrm{el} \rightarrow \mathrm{u}, \mathrm{k}}+E_{\mathrm{PV}, \mathrm{el} \rightarrow \mathrm{BES}, \mathrm{k}}+E_{\mathrm{PV}, \mathrm{el} \rightarrow \mathrm{GSHP}, \mathrm{k}}$

\subsection{Plant components}

The PV system is based on single-crystalline solar cells, where the overall efficiency is calculated as follows [15, 16]:

$$
\eta_{\mathrm{PV}}=\eta_{\mathrm{Bos}} \cdot \eta_{\mathrm{M}, \mathrm{ref}}\left[1-\beta \cdot\left(T_{\mathrm{c}}-T_{\mathrm{c}, \mathrm{ref}}\right)\right]
$$

where the balance of system ( $\left.\eta_{\mathrm{Bos}}\right)$ is assumed equal to 0.9 , the performance of the PV module $\left(\eta_{\mathrm{M} \text {,ref }}\right)$ is equal to 0.19 and the temperature penalty coefficient $(\beta)$ is equal to $0.005^{\circ} \mathrm{C}^{-1}$.

The efficiency of the STC is calculated by means of Eq. (7) [17]:

$$
\eta_{\mathrm{STC}}=\eta_{\mathrm{o}}-b_{1} \cdot K-b_{2} \cdot K^{2}
$$




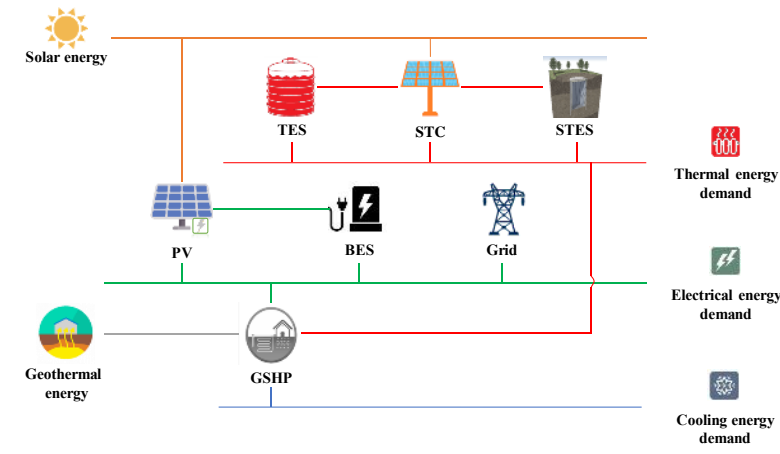

Fig. 1. Diagram of the renewable energy plant.

where the optical efficiency $\left(\eta_{\mathrm{o}}\right)$ is equal to $0.8 . b_{1}$ and $b_{2}$ are two correction factors and the variable $K$ depends on the external ambient temperature and the solar radiation.

The efficiency of the reversible GSHP is defined by the Coefficient of Performance $(C O P)$ in winter and the Energy Efficiency Ratio (EER) in summer. Thermal energy and cooling energy production are calculated as follows:

$P_{\mathrm{GSHP}, \mathrm{th}}=P_{\mathrm{GSHP}, \mathrm{el}} \cdot C O P$

(8)

$P_{\mathrm{GSHP}, \text { cool }}=P_{\mathrm{GSHP} . \mathrm{el}} \cdot E E R$

The COP and the EER, at nominal conditions, are assumed equal to 3.4 and 4.6, respectively [18]. Moreover, the GSHP performance is corrected as a function of the ground temperature by considering a stepwise linear function.

The TES is filled up by the excess thermal energy produced by the STC. The TES is a short-term thermal energy storage that can be charged and discharged hour by hour throughout the year. The thermal capacity of the TES expressed in [kWh] is calculated as reported in Eq. (10):

$$
E_{\mathrm{TES}, \mathrm{th}, \max }=\frac{V_{\mathrm{TES}} \cdot \rho_{\mathrm{w}} \cdot c_{\mathrm{w}} \cdot \Delta T}{3600}
$$

At each hour the energy available in the TES is updated as follows:

$$
\begin{array}{r}
E_{\mathrm{TES}, \mathrm{th}, \mathrm{k}+1}=\left(1-d_{\mathrm{diss}}\right) . \\
\left(E_{\mathrm{TES}, \mathrm{th}, \mathrm{k}}+E_{\mathrm{TES}, \mathrm{th}, \mathrm{in}, \mathrm{k}}-E_{\mathrm{TES}, \mathrm{th}, \text { out }, \mathrm{k}}\right)
\end{array}
$$

where $d_{\text {diss }}$ is a dissipation coefficient, which is considered equal to $0.5 \%$ per hour [19].

The STES is a long-term thermal energy storage, which is used on a seasonal basis, i.e. the STES is filled up by the excess of energy produced from the STC during summer and discharged during winter.

The STES is modelled by following the multi-node 1D approach reported by Cadau et al. [5]. According to the multi-node approach, the storage is divided into $\mathrm{N}$ nodes (in this paper $\mathrm{N}=11$ ), where each node represents a zone with a uniform temperature. The first node corresponds to the top of the storage (hottest zone), while the last node corresponds to the bottom of the storage (coldest zone).
The temperature variation for the ith node due to the energy from the STC, heat transfer between adjacent nodes and ambient losses is expressed as follows:

$$
\begin{gathered}
\Delta T_{\mathrm{STES}, \mathrm{i}, \mathrm{k}}=\frac{3600}{V_{\mathrm{STES}, \mathrm{i}} \rho_{\mathrm{w}} \cdot \mathrm{c}_{\mathrm{w}}} \cdot\left[E_{\mathrm{STES}, \mathrm{exch,i}}+\lambda_{\mathrm{w}} \cdot h_{\mathrm{STES}, \mathrm{i}} \cdot \Delta k \cdot\left(T_{\mathrm{i}-1}-T_{\mathrm{i}}\right)-\right. \\
\left.\lambda_{\mathrm{w}} \cdot h_{\mathrm{STES}, \mathrm{i}} \Delta k \cdot\left(T_{\mathrm{i}}-T_{\mathrm{i}+1}\right)-U \cdot A_{\mathrm{STES}, \mathrm{i}} \cdot \Delta k \cdot\left(T_{\mathrm{i}}-T_{\mathrm{amb}}\right)\right]
\end{gathered}
$$

The water conduction constant $\lambda_{\mathrm{w}}$ is equal to 0.644 $\mathrm{W} /(\mathrm{m} \cdot \mathrm{K})$, the overall heat exchange coefficient is assumed equal to $0.366 \mathrm{~W} /\left(\mathrm{m}^{2} \cdot \mathrm{K}\right)$ for the lateral and bottom areas, while for the top a coefficient of 0.180 $\mathrm{W} /\left(\mathrm{m}^{2} \cdot \mathrm{K}\right)$ is assumed [20]. Moreover, the maximum temperature achievable in the STES is assumed equal to $90{ }^{\circ} \mathrm{C}$, while the minimum temperature is set equal to the temperature of the ground (around $14{ }^{\circ} \mathrm{C}$ ). It should be mentioned that the minimum temperature at which the thermal energy from the STES can be used for space heating is assumed equal to $40{ }^{\circ} \mathrm{C}$.

In order to store the excess of electricity produced from the PV system, rechargeable lithium-ion batteries are modelled. The BES interacts with the PV system via an inverter considering a charging/discharging efficiency equal to 0.9 [21]. At each hour, the available energy in the BES after one cycle of charging/discharging is defined as reported in Eq. (13):

$$
\begin{aligned}
& E_{\mathrm{BES}, \mathrm{el}, \mathrm{k}+1}=E_{\mathrm{BES}, \mathrm{el}, \mathrm{k}}+\eta_{\mathrm{BES}, \mathrm{ch}} \cdot E_{\mathrm{BES}, \mathrm{el}, \mathrm{in}, \mathrm{k}}- \\
& \eta_{\mathrm{BES}, \mathrm{dis}} \cdot E_{\mathrm{BES}, \mathrm{el}, \mathrm{out}, \mathrm{k}}
\end{aligned}
$$

\section{Case study}

The tuned methodology is applied to the Campus of the University of Parma (Italy) that accounts for 21 buildings dedicated to both educational and scientific research activities, located over an area of approximately 77 ha $[10,11]$. Currently, thermal and cooling energy demands are met by means of five natural gas boilers and four compressor refrigeration units, respectively. Finally, the campus is connected to the national electrical grid $[11,12]$.

Figure 2 shows thermal, cooling and electrical energy demands over one year. It is worth noting that the considered timeframe starts on 15th April, i.e., when the heating period of the given climatic zone ends, so that the STES is first charged by the STC during summer and mid-season and subsequently discharged in winter period. Otherwise, starting from the beginning of the year (i.e., January), a simulation of the plant over multiple years would be needed.

Hourly energy demand profiles were both experimentally collected and obtained by means of physical models. Because of confidentiality reasons, each energy demand was normalized with respect to its corresponding peak value.

The hourly profile of the ambient temperature was achieved from [11], while hourly profiles of solar radiation corresponding to the considered thermal climate zone, i.e., zone A, are calculated according to [22] and [23]. It is worth noting that the solar radiation profile identified for each month refers to one representative day. 

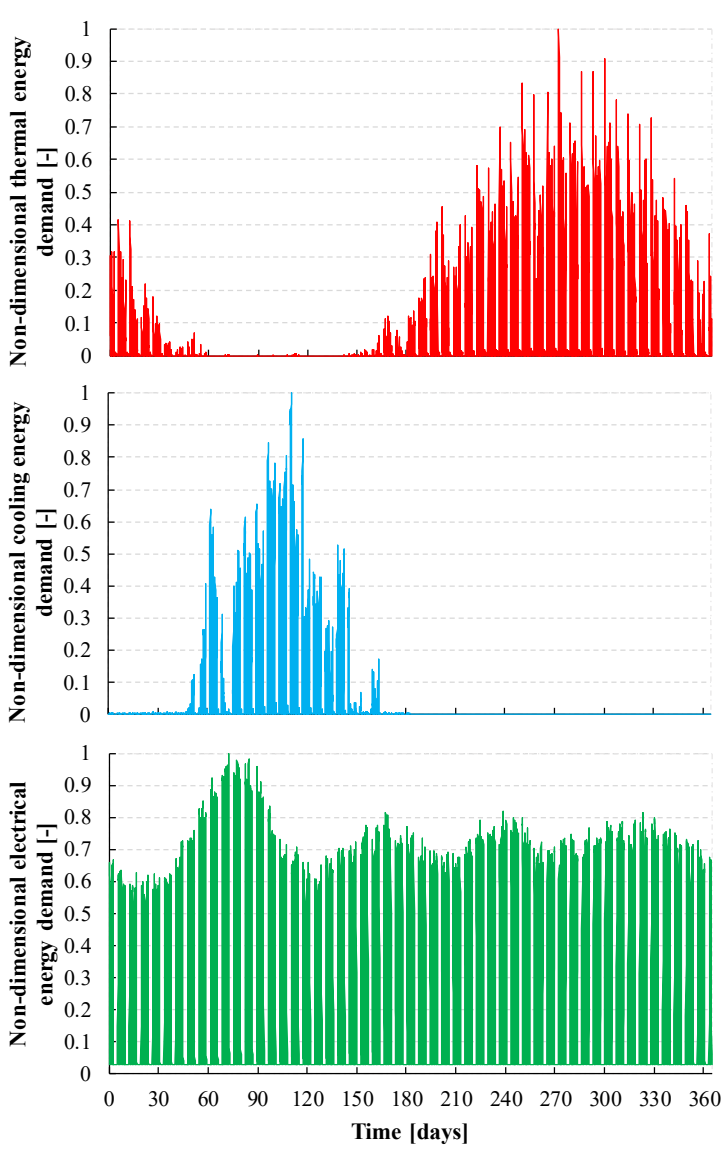

Fig. 2. Non-dimensional values of hourly thermal, cooling and electrical energy demands profiles

Two Scenarios, called A and B, are analysed in this paper. The available area considered for the PV and STC systems in Scenario B is 2.5 times the available area in Scenario A, which is the maximum area that can be covered by solar cells and collectors in the campus (e.g. free rooftop area).

\section{Results}

The optimization results for the two scenarios (A and B) are reported in Table 1. The PV and STC areas are normalized with respect to the available area in Scenario $\mathrm{B}$, the GSHP size is normalized with respect to the cooling peak power of the campus, while the capacities of the TES/STES and BES are expressed in hours by dividing their capacities by the thermal and electrical peak power, respectively.

With reference to Scenario A, the available area is fully covered by the STC. In Scenario B, 30\% of the available area is covered by the PV system. For both scenarios, the GSHP is sized equal to the peak of the cooling power of the campus. This is mainly due to the fact that the reversible GSHP is only used to meet the cooling energy demand. TES and STES are characterized by larger capacities in Scenario A. Finally, in Scenario A, the BES is not used, since the PV area is zero.

Figure 3 highlights the contribution of the REP components to the thermal energy demand. In Scenario A, most of the thermal energy demand is met through the STES, while a higher fraction is directly met by the STC in Scenario B.

Table 1. Optimal sizes of plant components.

\begin{tabular}{|c|c|c|c|}
\hline & & $\begin{array}{c}\text { Scenario } \\
\text { A }\end{array}$ & $\begin{array}{c}\text { Scenario } \\
\text { B }\end{array}$ \\
\hline $\mathrm{PV}$ & $A_{\mathrm{PV}} / A_{\text {available,Scenario B }}[-]$ & 0 & 0.3 \\
\hline $\mathrm{STC}$ & $A_{\mathrm{STC}} / A_{\text {available,Scenario B }}[-]$ & 0.4 & 0.7 \\
\hline $\mathrm{GSHP}$ & $P_{\mathrm{GSHP}, \text { cool,nom }} / P_{\text {user,cool,peak }}[-]$ & 1.0 & 1.0 \\
\hline $\mathrm{TES}$ & $E_{\mathrm{TES}, \mathrm{h}, \max } / P_{\text {user,th,peak }}[\mathrm{h}]$ & 2.4 & 1.5 \\
\hline $\mathrm{STES}$ & $E_{\mathrm{STES}, \mathrm{th}, \max } / P_{\text {user,th,peak }}[\mathrm{h}]$ & 472.1 & 327.1 \\
\hline $\mathrm{BES}$ & $E_{\mathrm{BES}, \mathrm{el}, \max } / P_{\text {user,el,peak }}[\mathrm{h}]$ & 0 & 1.6 \\
\hline
\end{tabular}

This can be explained by the fact that the STC in Scenario B covers a bigger area and is able to meet a higher fraction of the energy demand. Consequently, the STES in Scenario B is characterized by a smaller capacity and its production is reduced to $37 \%$.

Since the GSHP is the only system used to meet the cooling energy demand, for both scenarios, the cooling energy demand is met by this system.

Regarding the contribution to the electrical energy demand (Fig. 4), 17\% of the demand (i.e. the sum of the electrical demand of the campus and the GSHP) is met by the PV and BES in Scenario B. Consequently, this allows a reduction of the electrical energy taken from the grid. However, in order to tackle a $100 \%$ renewable energy production, a larger area for PV panels is needed.

Figure 5 shows the contribution of the different systems to the thermal energy demand normalized to the peak of the daily energy demand of the campus. In this Figure, the negative values for the TES and the STES stand for the respective energy entering the storage. As can be seen, during the mid-season and summer, the STES is filled up by the STC and then is used during cold season to meet the thermal energy peaks.

Compared to Scenario B, the STC covers a smaller area in Scenario A and it takes longer to fill up the STES, of which the capacity is about 1.4 the STES used in Scenario B. However, in order to keep the temperature inside the STES at high levels, for both scenarios, the STC continues to fill the storage. In fact, in order to preserve the energy inside the tank, the energy released to the surrounding ground must be provided by the STC.
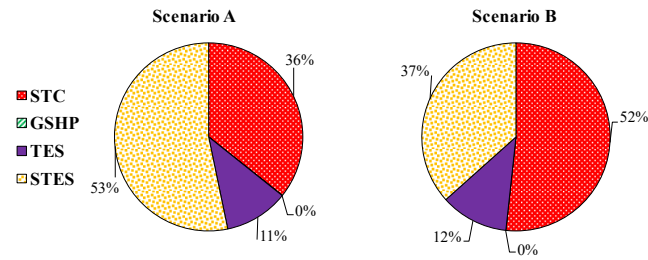

Fig. 3. Contribution to the thermal energy demand for Scenario A and Scenario B. 


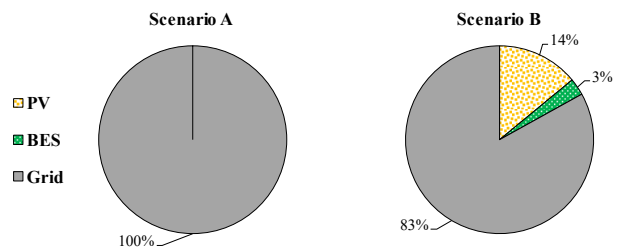

Fig. 4. Contribution to the electrical energy demand for Scenario A and Scenario B.

In Scenario A, the thermal energy lost to the environment is about $16 \%$ of the energy charged by the STC. Instead, the lost energy increases to about $20 \%$ in Scenario B. In fact, in Scenario B, the STC is required to maintain the whole STES at $90{ }^{\circ} \mathrm{C}$ (Fig. 6, Scenario B) for a longer period and compensate the losses which are proportional to the difference between the temperature of the water and the temperature of the ground.

The temperature profiles within the STES throughout one year are reported in Fig. 6 for both scenarios. During the charging period, the temperature increases in the STES up to the maximum temperature, starting from the TOP (Node 1) to the BOTTOM (Node 11). As can be noted, compared to the other nodes, the decrease of temperature is much faster at the BOTTOM (Node 11) because it has a bigger area in contact with the environment.

As mentioned before, the STES in Scenario B is filled up faster and consequently the temperature inside the tank rises more rapidly.

\section{Conclusions}

In this study, a $100 \%$ renewable energy plant was optimally designed and managed from an energy perspective. The considered plant includes a photovoltaic system, a solar thermal collector, a ground source heat pump, a thermal energy storage, a seasonal energy storage and a battery energy storage. Two scenarios, named Scenario A and Scenario B, are investigated; the available area in Scenario B is 2.5 times the available area in Scenario A. A genetic algorithm was implemented to solve the optimization problem with the aim of minimizing the electricity taken from the grid.

It was found that, in Scenario A, thanks to the integration of the seasonal energy storage, the plant was able to meet the whole thermal energy demand by fully exploiting solar power. However, the cooling energy demand was only partially met by the geothermal energy harvested by the ground source heat pump, while the electrical energy demand of the campus and heat pump was fully provided by the grid. In Scenario B, the increase of the available area allows meeting $17 \%$ of the electrical energy demand by means of the photovoltaic system and the batteries, thus reducing the energy supply from the grid. However, in order to achieve $100 \%$ renewable energy target, more available area would be needed.

Since the electrical energy taken from the grid is mainly used to meet the cooling and electrical energy demands, future works will focus on upgrading the current plant by integrating an absorption chiller and/or an organic Rankine cycle.

\section{Acknowledgements}

This paper was carried out in the framework of the research program "ENERGYNIUS - ENERGY Networks Integration for Urban Systems (PG/2018/632084)".

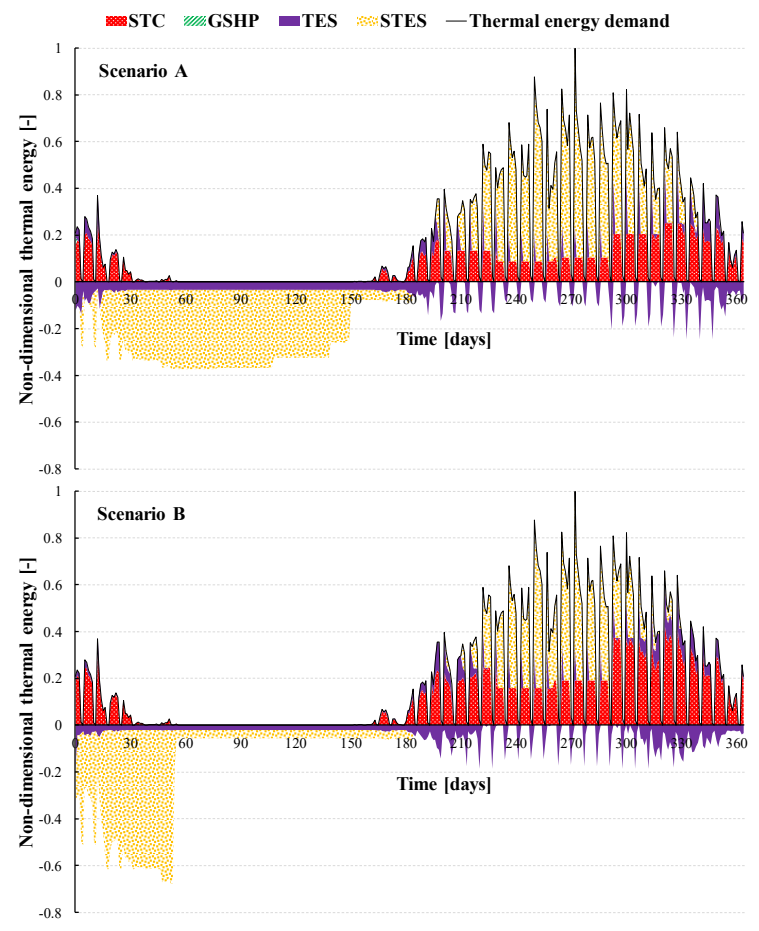

Fig. 5. Daily thermal energy production of the plant components for Scenario A and Scenario B.

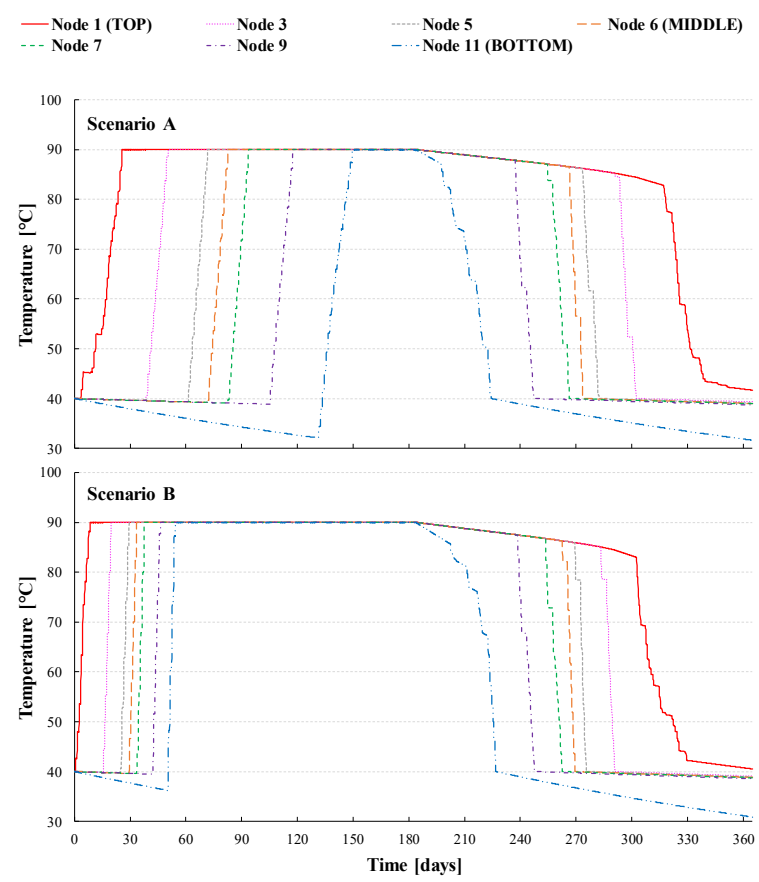

Fig. 6. Temperature profiles inside the seasonal storage for Scenario A and Scenario B. 


\section{References}

[1] T. Luz, P. Moura, Appl. Energy, 255 (2019), 113819

[2] M. Child, D. Bogdanov, C. Breyer, Energy Procedia, 155 (2018), 390-402

[3] J.Z. Thellufsena, H. Lunda, P. Sorknæsa, P.A. Østergaarda, M. Changa, D. Drysdaleb, S. Nielsena, S.R. Djørupa, K. Sperlinga, Renew. Sust. Energ. Rev., 129 (2020), 109922

[4] J.P. Jimenez-Navarroa, K. Kavvadiasa, F. Filippidoua, M. Pavičevićb, S. Quoilinb, Appl. Energy, 270 (2020), 115134

[5] N. Cadau, A. De Lorenzi, A. Gambarotta, M. Morini, M. Rossi, Energies, 12 2019, 4275

[6] E. Guelpa, V. Verda, Appl. Energy, 252 (2019), 113474

[7] P.A. Sørensen, T. Schmidt, Design and Construction of Large Scale Heat Storages for District Heating in Denmark, 14th International Conference on Energy Storage, 25-28 April 2018, Adana, Turkey

[8] H. Saboori, R. Hemmati, S. Mohammad, S. Ghiasi, S. Dehghanc, Renew. Sust. Energ. Rev., 79 (2017), 1108-1121

[9] M. Van der Kam, W. Van Sark, AppL. Energy, 152 (2015), 20-30

[10] H. Bahlawan, A. Gambarotta, E. Losi, L. Manservigi, M. Morini, P.R Spina, M. Venturini, J. Eng. Gas. Turb. Power (to be published)

[11] M. Zatti, M. Gabba, M. Freschini, M. Rossi, A. Gambarotta, M. Morini, E. Martelli, Energy, 181 (2019), 1051-1063

[12] M. Zatti, M. Gabba, M. Rossi, M Morini, A. Gambarotta, E. Martelli, Environ. Eng. Manag. J., 17 (2018), No. 10, 2409-2419

[13] C. Bott, I. Dressel, P. Bayer, Renew. Sust. Energ. Rev., 113 (2019), 109241

[14] H. Bahlawan, M. Morini, M. Pinelli, W.R Poganietz, P.R. Spina, M. Venturini, Appl. Energy, 253 (2019), 113484

[15] F. Kreith, D.Y. Goswami, Handbook of energy efficiency and renewable energy. CRC Press (2007)

[16] D. Cocco, C. Palomba, P. Puddu, Tecnologie delle energie rinnovabili. SG Editoriali, Padova (2008)

[17] L. Rubini, S. Sangiorgio, Le energie rinnovabili. Hoelpi, Milano (2012)

[18] E.S. Barbieri, M. Morini, E. Munari, M. Pinelli, P.R. Spina, R. Vecci, Energy Procedia, 81 (2015), 45-54

[19] A. Gambarotta, M. Morini, N. Pompini, P.R. Spina, Energy Procedia, 81 (2015), 30-39

[20] Y. Bai, Z. Wang, J. Fan, M. Yang, X. Li, L. Chen, G. Yuan, J. Yang, Renew. Energ., 150 (2020), 487-508

[21] M. Van der Kam, W. Van Sark, Appl. Energy, 152 (2015), 20-30

[22] Ente Italiano di Normazione, UNI TS 11300; 2012 [In Italian]

[23] Ente Italiano di Normazione, UNI 10349; 2016 [In Italian]

\section{Nomenclature}

$\underline{\text { Abbreviations }}$

$\begin{array}{ll}\text { BES } & \text { Battery Energy Storage } \\ \text { BoS } & \text { Balance of System } \\ \text { COP } & \text { Coefficient of Performance } \\ \text { EER } & \text { Energy Efficiency Ratio } \\ \text { GA } & \text { Genetic Algorithm } \\ \text { GSHP } & \text { Ground Source Heat Pump } \\ \text { PV } & \text { Photovoltaic system } \\ \text { REP } & \text { Renewable Energy Plant } \\ \text { RES } & \text { Renewable Energy Source } \\ \text { STC } & \text { Solar Thermal Collector } \\ \text { STES } & \text { Seasonal Thermal Energy Storage } \\ \text { TES } & \text { Thermal Energy Storage }\end{array}$

$\underline{\text { Symbols }}$

A area

$b \quad$ coefficient

$d \quad$ dissipation coefficient

E energy

$h \quad$ height

$k \quad$ time step

$K \quad$ variable

$P \quad$ power

$T \quad$ temperature

$U \quad$ overall heat exchange coefficient

$V \quad$ volume

$\beta \quad$ temperature penalty coefficient

$\Delta \quad$ variation

$\eta \quad$ efficiency

$\rho \quad$ density

$\lambda \quad$ water conduction constant

\section{$\underline{\text { Subscripts and Superscripts }}$}

$\begin{array}{ll}\begin{array}{l}\text { Amb } \\ \text { ch }\end{array} & \begin{array}{l}\text { ambient } \\ \text { charging }\end{array} \\ \text { cool } & \text { cooling } \\ \text { dis } & \text { discharge } \\ \text { diss } & \text { dissipation } \\ \text { el } & \text { electrical } \\ \text { grid } & \text { electric grid } \\ \text { i } & \text { node label } \\ \text { in } & \text { input } \\ \text { M } & \text { module } \\ \text { max } & \text { maximum } \\ \text { nom } & \text { nominal } \\ \text { out } & \text { output } \\ \text { ref } & \text { design condition } \\ \text { th } & \text { thermal } \\ \text { user } & \text { user } \\ \text { W } & \text { water }\end{array}$

